\title{
High-pressure Polymorphs of LaHO with Anion Coordination Reversal
}

\author{
Thibault Broux, ${ }^{\mathrm{a}}$ Hiroki Ubukata, ${ }^{\mathrm{a}}$ Chris J. Pickard, ${ }^{\text {b,c }}$ Fumikata Takeiri, ${ }^{\mathrm{d}}$ Genki Kobayashi, ${ }^{\mathrm{d}}$ Shogo Ka- \\ waguchi, ${ }^{\mathrm{e}}$ Masao Yonemura, ${ }^{\mathrm{f}}$ Yoshihiro Goto, ${ }^{\mathrm{a}}$ Cédric Tassel, ${ }^{\mathrm{a}}$ and Hiroshi Kageyama*a \\ ${ }^{a}$ Graduate School of Engineering, Kyoto University, Kyoto 615-8510 Japan \\ ${ }^{\mathrm{b}}$ Department of Materials Science \& Metallurgy, University of Cambridge, 27 Charles Babbage Road, Cambridge, (UK) \\ c Advanced Institute for Materials Research, Tohoku University 2-1-1 Katahira, Aoba, Sendai, 980-8577, Japan \\ d Department of Materials Molecular Science, 38 Nishigonaka, Myodaiji, Okazaki 444-8585, Japan \\ e Japan Synchrotron Radiation Research Institute, SPring-8, 1-1-1 Kouto, Sayo-cho, Sayo-gun, Hyogo 679-5198, Japan
}

${ }_{\mathrm{f}}^{\mathrm{f}}$ Neutron Science Laboratory (KENS), Institute of Materials Structure Science, High Energy Accelerator Research Organization, 203-1 Shirakata, Tokai, Ibaraki 319-1106, Japan

\section{Supporting Information Placeholder}

\begin{abstract}
Two novel high-pressure polymorphs of lanthanum oxyhydride have been successfully predicted and stabilized under pressure. When reacted at $3 \mathrm{GPa}$, the fluorite structure of $\mathrm{LaHO}$ with anion-centered tetrahedral $\left(\mathrm{HLa}_{4} / \mathrm{OLa}_{4}\right)$ geometry is transformed to the $\mathrm{PbCl}_{2}$-type structure involving coordination number increase of $\mathrm{H}^{-}$to five ( $\mathrm{HLa}_{5}$ square pyramids). Upon further application of pressure to $5 \mathrm{GPa}$, LaHO changed into the anti $\mathrm{Fe}_{2} \mathrm{P}$-type structure. Interestingly, the $5 \mathrm{GPa}$ phase contains tetrahedral $\mathrm{HLa}_{4}$ and square-pyramidal OLa 5 geometry, meaning coordination switching, as confirmed by ab initio calculations. The structural analysis shows that this unprecedented phenomenon is enabled by higher compressibility of hydride anion and emphasizes its potential in the search for new high-pressure forms of hydride-based materials.
\end{abstract}

High-pressure synthesis offers an access to new compounds that exhibit novel chemical and physical functions. ${ }^{1}$ Among highpressure polymorphs, the most well-known is diamond which finds a wide variety of applications. Application of pressure to a ferromagnetic $\alpha-\mathrm{Fe}$ induces a structural transition to $\varepsilon$-Fe and leads to superconductivity at low temperature. ${ }^{2}$ Furthermore, meta-stable superhydrides exhibit high- $T_{\mathrm{c}}$ superconductivity under megabar pressures: $\mathrm{H}_{3} \mathrm{~S}$ at $T_{\mathrm{c}}=203 \mathrm{~K}^{3}$ and $\mathrm{LaH}_{10}$ at $T_{\mathrm{c}}=260 \mathrm{~K}^{4}$

High-pressure polymorphs have structures with higher density, and this is enabled, for example, by forming closest-packed arrays of atoms (e.g., hexagonal closed packed (hcp) $\varepsilon$-Fe vs bodycentered cubic $\alpha-\mathrm{Fe}$ ) and by altering bonding character (e.g., diamond vs graphite). In ionic compounds, high pressure often leads to an increase of coordination number. ${ }^{5}$ In the first case for instance, the transformation from $\mathrm{NaCl}$-type to $\mathrm{CsCl}$-type structures involving a coordination change of 6 to 8 occurs in binary halides, ${ }^{6}$ oxides, ${ }^{7}$ chalcogenides, ${ }^{8}$ and intergrowth compounds. ${ }^{9}$ Similarly, tetrahedrally coordinated $\mathrm{SiO}_{2}$ have various highpressure forms such as rutile-type phase with octahedral coordination $^{10}$
Recent studies on oxyhydrides have revealed novel properties (e.g., hydride conductivity and heterogeneous catalysis) associated with unique features of the hydride anion, such as lability and high polarizability. ${ }^{11-16}$ Our study on $\mathrm{SrVO}_{2} \mathrm{H}$ revealed that the $\mathrm{V}-\mathrm{H}-\mathrm{V}$ distance decreases twice as large as the $\mathrm{V}-\mathrm{O}-\mathrm{V}$ distance, indicating that $\mathrm{H}^{-}$anion is extraordinary compressible. ${ }^{17}$ The size flexibility of $\mathrm{H}^{-}$was then exploited to enable a novel anion orderdisorder transition in $\mathrm{LnHO} .{ }^{18}$ For $\mathrm{Ln}=\mathrm{Sm}-\mathrm{Er}$ with smaller ionic radii $\left(R_{\mathrm{Ln}}\right), \mathrm{LnHO}$ adopts the anion-disordered fluorite structure. Since the $\mathrm{O}^{2-}$ anion becomes gradually under-bonded with increasing $R_{\text {Ln }}$ (i.e., application of negative chemical pressure), anion ordering takes place for $\mathrm{Ln}=\mathrm{La}-\mathrm{Nd}$ (Figure 1a), where $\mathrm{H}^{-}$ anions are expanded to form a larger $\mathrm{HLn}_{4}$ tetrahedron, resulting in a smaller $\mathrm{OLn}_{4}$ tetrahedron. Based on this result, we hypothesized that the application of external pressure to the anion-ordered LnHO induces anion-disorder. However, we unexpectedly obtained two polymorphs which exhibit unprecedented anion coordination reversal.

Since the previously used metathesis synthesis $\left(\mathrm{Ln}_{2} \mathrm{O}_{3}+\mathrm{CaH}_{2}\right.$ $\rightarrow 2 \mathrm{LnHO}+\mathrm{CaO})^{18,19}$ is unsuitable for a high-pressure setup, we employed a direct reaction using a cubic anvil apparatus, as used in the synthesis of perovskite-based oxyhydrides. ${ }^{20,21}$ Lanthanum sesquioxide and lanthanum hydride in a molar ratio 1:1 were mixed, pressed up to 1,3 and $5 \mathrm{GPa}$, heated at $900{ }^{\circ} \mathrm{C}$ for 1 hour. The synchrotron X-ray diffraction (SXRD) profile (Figure 2a) showed that the sample prepared at $1 \mathrm{GPa}$ is the same as the ambient LaHO phase with the anion-ordered fluorite structure (Figure 1a). ${ }^{22}$ The cell parameters of $a=8.0765(2) \AA$ and $c=$ 5.7257(2) $\AA$ are quite close to those of reported. This phase will be denoted as $\alpha$-LaHO by analogy with predicted $\mathrm{CaF}_{2}$ polymorphs. ${ }^{23} \alpha$-LaHO contains three independent lanthanide sites, all in eightfold $(\mathrm{H} \times 4, \mathrm{O} \times 4)$ and nearly cubic environments. ${ }^{22}$ As reported previously, from the anion-centered viewpoint, both anions lie in tetrahedral environments, but with distinct volumes of $8.15 \AA^{3}$ for $\mathrm{HLa}_{4}$ and $7.39 \AA^{3}$ for OLa 4 . 


\section{a) Ambient pressure}
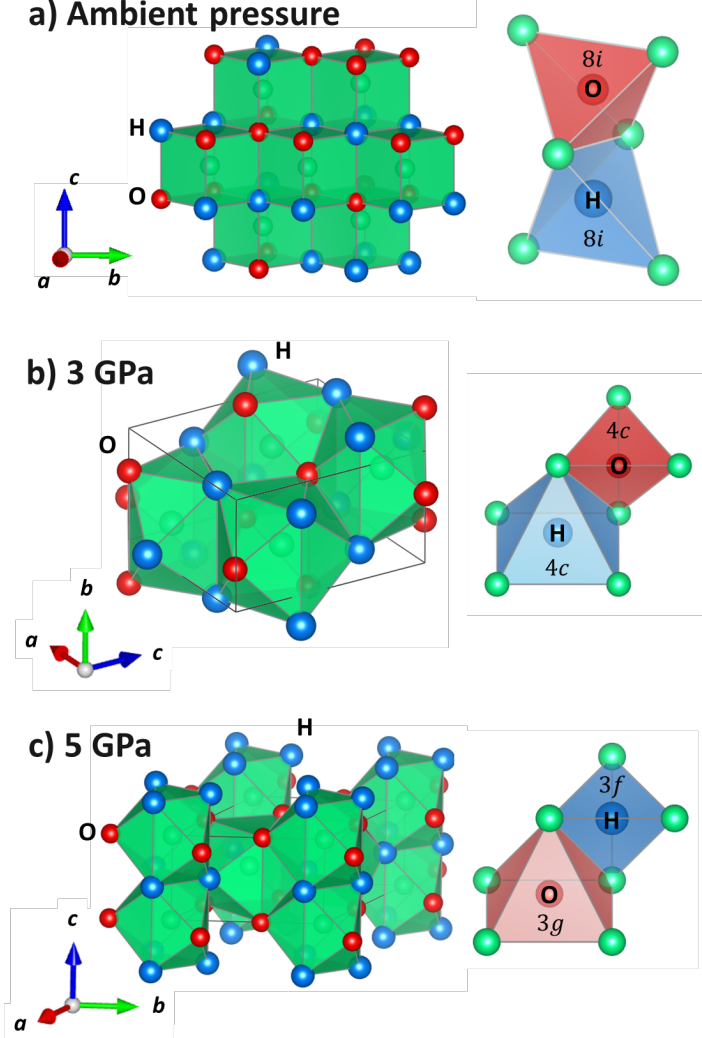

Figure 1. Crystal structures (a) $\alpha$-LaHO at ambient pressure (and $1 \mathrm{GPa})$ crystalizing in the anion-ordered fluorite structure ( $P 4 / \mathrm{nmm}$ ) with $\mathrm{LaO}_{4} \mathrm{H}_{4}$ local coordination, ${ }^{22}$ (b) $\gamma$-LaHO $(P n m a)$ at $3 \mathrm{GPa}$ with $\mathrm{LaO}_{4} \mathrm{H}_{5}$ and (c) $\delta$-LaHO $(P \overline{6} 2 m)$ at $5 \mathrm{GPa}$ with $\mathrm{LaO}_{5} \mathrm{H}_{4}$. The right panels represent the coordination geometry around the hydride and oxide anion, (a) HLa 4 and OLa, (b) $\mathrm{HLa}_{5}$ and $\mathrm{OLa}_{4}$, (c) $\mathrm{HLa}_{4}$ and $\mathrm{OLa}_{5}$. Red, blue and green spheres

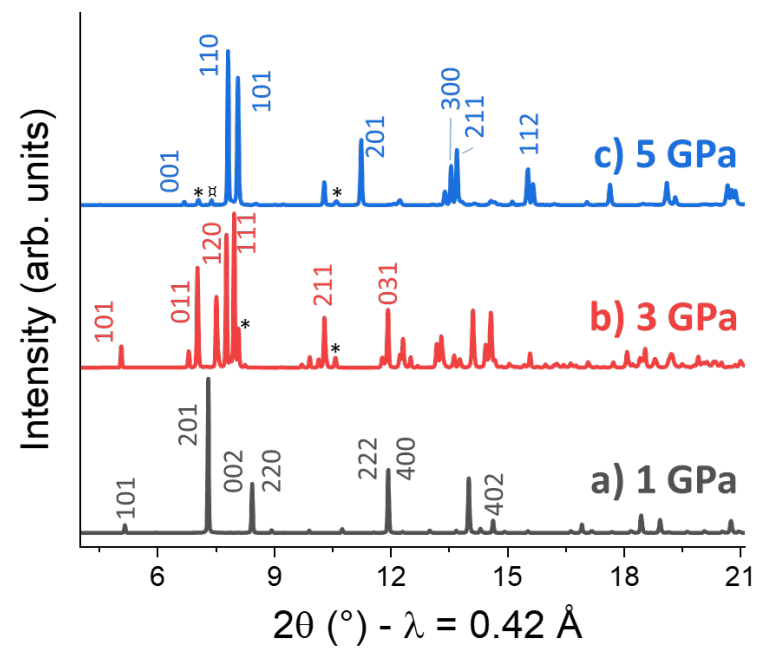

denote $\mathrm{O}, \mathrm{H}$ and $\mathrm{La}$ atoms, respectively.

Figure 2. SXRD patterns of $\mathrm{LaHO}$ synthesized at $900{ }^{\circ} \mathrm{C}$ under a pressure of (a) $1 \mathrm{GPa}$, (b) $3 \mathrm{GPa}$ and (c) $5 \mathrm{GPa}$. Unreacted precursors peaks are denoted by $*$ for $\mathrm{La}_{2} \mathrm{O}_{3}$ and $\mathrm{a}$ for $\mathrm{LaH}_{3}$.

By applying pressure up to $3 \mathrm{GPa}$, a completely different SXRD pattern (Figure 2b) is obtained, which can be indexed by an orthorhombic cell of $a=6.41 \AA, b=3.92 \AA$ and $c=7.08 \AA$, except for small impurity peaks. A similar unit cell is found in compounds with the $\mathrm{PbCl}_{2}$-type structure (space group Pnma) such as $\mathrm{CaH}_{2}(a=5.95 \AA, b=3.61 \AA, c=6.85 \AA),{ }^{24} \mathrm{SrH}_{2}, \mathrm{BaH}_{2}$ and $\mathrm{CaF}_{2}$ at $9.5 \mathrm{GPa} .{ }^{25}$ The cation arrangement in the $\mathrm{PbCl}_{2}$ structure is given by a distorted hcp, with anions in tetrahedral $\left(\mathrm{ClPb}_{4}\right)$ and square-pyramidal $\left(\mathrm{ClPb}_{5}\right)$ coordination. Synchrotron/neutron Rietveld refinements successfully converged to the agreement factors of $R_{\mathrm{Bragg}}=3.51 \% / 3.40 \%$ and $R_{\mathrm{wp}}=11.1 \% / 4.64 \%$ (Table $\mathrm{S} 1)$ when oxide and hydride anions were placed, respectively, at the four- and five-coordinated site (Figure 1b). The neutron refinement shows that the anion occupancies stayed at 1 . Bond valence sum (BVS) calculation using tabulated parameters ${ }^{26}$ yielded $\mathrm{La}=+3.30(1), \mathrm{O}=-2.19(1)$ and $\mathrm{H}=-1.11(1)$, which is in good agreement with their formal valences. We call the $3 \mathrm{GPa}$ phase as $\gamma$-LaHO by analogy with $\mathrm{CaF}_{2}$ polymorphs. ${ }^{23}$ As for multiple anion system, M. Glätzle et al. recently reported that LnOF oxyfluorides $(\mathrm{Ln}=\mathrm{Nd}, \mathrm{Sm}, \mathrm{Eu})$ adopt the $\mathrm{PbCl}_{2}$-type structure when synthetized under pressure $(11 \mathrm{GPa}){ }^{27}$

The observed pressure-induced transition $(\alpha \rightarrow \gamma)$ in LaHO is understandable from various angles. Firstly, the density increases by $5 \%$ from 5.54 to $5.82 \mathrm{~g} / \mathrm{cm}^{3}$. Secondly, the cation-coordination increases from $8(\mathrm{H} \times 4, \mathrm{O} \times 4)$ to $9(\mathrm{H} \times 5, \mathrm{O} \times 4)$ and $\mathrm{La}^{3+}$ cations adopt a more closely-packed (hcp) arrangement. Regarding the anion, only the hydride increases its coordination number from 4 to 5 . Note also that the $\mathrm{OLa}_{4}$ tetrahedral volume reduces only slightly $\left(6.94 \AA^{3}\right.$ ). The increased coordination in $\mathrm{H}^{-}$(not in $\left.\mathrm{O}^{2-}\right)$ is in line with the fact that a structural modification under pressure takes place in general by imposing a distortion to atoms with weaker bonds. ${ }^{28}$ Here the La-H bonding should be weaker than $\mathrm{La}-\mathrm{O}$ in terms of valence $(-1 v s-2)$ and the average bond distance (2.52 $\AA$ vs $2.44 \AA$ for $\alpha$ phase). The pressure-induced $\alpha-$ $\gamma$ transition in $\mathrm{LnOF}^{27}$ can also be understood in the same manner. The important difference, however, is that $\mathrm{LnOF}$ requires a much higher pressure of $11 \mathrm{GPa}$ to stabilize the $\gamma$ form. Much lower critical pressure in $\mathrm{LaHO}(3 \mathrm{GPa})$ could be ascribed to weaker bond strength for $\mathrm{La}-\mathrm{H}$ than $\mathrm{La}-\mathrm{F}$, as demonstrated in fluorides, chlorides and hydrides with transition metals. ${ }^{29}$

In parallel to the experimental approach, $a b$ initio random structure searching (AIRSS) $)^{31,32}$ has been performed on LaHO at different pressures, similarly to the approach taken for the high pressure phases of group-II difluorides. ${ }^{32}$ The CASTEP $\operatorname{cod}^{33}$ was employed to perform the structural optimizations through the density functional PBEsol. ${ }^{34}$ Structure files containing the full computational details are provided in Supporting Information. The results obtained confirm our experimental observations where the $\mathrm{PbCl}_{2}$ structure type was identified as a stable denser structure compared to fluorite.

When the synthesis pressure was further increased to $5 \mathrm{GPa}$, we again encountered a drastic change in the X-ray diffraction pattern. The new pattern (Figure 1c) was indexed by a hexagonal cell $(a=6.17 \AA, c=3.60 \AA)$. Literature search has revealed that the $\mathrm{Fe}_{2} \mathrm{P}$-type structure $(P \overline{6} 2 \mathrm{~m})$ is a candidate. Although $\mathrm{US}_{2},{ }^{35}$ $\mathrm{USe}_{2},{ }^{35} \mathrm{BaCl}_{2},{ }^{36}$ and $\mathrm{BaI}_{2}{ }^{37}$ adopt this structure, oxides, fluorides and hydrides are not known to date. For anions, we initially placed $\mathrm{O}^{2-}$ and $\mathrm{H}^{-}$, respectively, at a tetrahedral $(3 f)$ and squarepyramidal $(3 g)$ site, as observed in the $\gamma$-phase ( $3 \mathrm{GPa})$, but this resulted in poor agreement (see the neutron refinement in Figure $\mathrm{S} 2$ ). A remarkable improvement has been obtained when the two anionic sites were swapped, giving $R_{\mathrm{Bragg}}=4.72 \% / 2.65 \%$ and $R_{\mathrm{wp}}$ $=6.74 \% / 3.28 \%$ for synchrotron $/$ neutron data (Figure $1 \mathrm{c}$, Table $\mathrm{S} 2)$. Neither anti-site $(\mathrm{H} / \mathrm{O})$ disorder nor anion deficiency was observed. Remarkably, this structure $(\delta$-LaHO) has been included in the structures predicted by AIRSS (Table S3, Figure S4). 
One can also justify the second transition from $\gamma$-LaHO to $\delta$ LaHO by the density increase from 5.82 to 6.54 . However, the most distinct feature of this transition is the reversed coordination environment around the anions: $\mathrm{HLa}_{5}$ and $\mathrm{OLa}_{4}$ in $\gamma$-LaHO change into $\mathrm{HLa}_{4}$ and $\mathrm{OLa}_{5}$ in $\delta$-LaHO. As far as we are aware, the reduction in coordination number by pressurization ( $\mathrm{HLa}_{5} \rightarrow$ $\mathrm{HLa}_{4}$ ) has never been reported. We believe the hydride compressibility plays a predominant role in this coordination reversal. In fact, $\mathrm{HLa}_{4}$ tetrahedra are significantly compressed from 8.15 to $6.6 \AA^{3}(\gamma \rightarrow \delta ; 19 \%)$, three times greater than $\mathrm{OLa}_{4}$ tetrahedra with a compression from 7.39 to $6.94 \AA^{3}(\alpha \rightarrow \delta ; 6 \%)$. The BVS calculations for $\delta$-LaHO show a reasonable value of -1.7 for oxide, but the value of -1.8 for hydride is much higher than that of the $\gamma$ phase. The apparent over-bonded $\mathrm{H}^{-}$merely implies a difficulty in evaluating BVS for hydride with the ability to flexibly change its size. ${ }^{17}$

$\mathrm{LaH}_{2.3}$ with the fluorite structure is phase-segregated into $\mathrm{LaH}_{2+x}$ and $\mathrm{LaH}$ at $10 \mathrm{GPa}^{38}$ This fact underlines the role of multiple anions with distinct compressibility for the realization of anion-coordination reversal. We believe that this concept can be extended to other oxyhydrides and more generally hydridefluorides and hydride-nitrides. Since high pressure phases of $\mathrm{CaF}_{2}$ have been theoretically predicted to be excellent ionic conductors, ${ }^{23,32} \alpha$-LaHO, $\gamma$-LaHO and $\delta$-LaHO may also be a potential candidate for hydride conductors, possibly after introduction of appropriate anion vacancy by aliovalent cation substitution. Higher pressure study is also of great interest. AIRSS searches on LaHO up to $100 \mathrm{GPa}$ has predicted a further transition to a hexagonal $\left(P 6_{3} m m c\right)$ structure with $\mathrm{HLa}_{5}$ bipyramidal and $\mathrm{OLa}_{6}$ octahedral coordination (Figures S5, S6).

\section{ASSOCIATED CONTENT}

\section{Supporting Information}

Experimental details including synthesis methods, materials characterization and additional data are given in supporting information.

The Supporting Information is available free of charge on the ACS Publications website.

\section{AUTHOR INFORMATION}

\section{Corresponding Author}

kage@scl.kyoto-u.ac.jp

\section{ACKNOWLEDGMENT}

This work was supported by CREST (JPMJCR1421), JSPS KAKENHI (JP17H06439, JP16H06441, JP15H03849), PRESTO (JPMJPR1441), Core-to-Core Program (A) Advanced Research Networks, and JSPS postdoctoral fellowship (TB). Experiments at the Diamond Light Source were performed as part of the Block Allocation Group award (EE13284). The neutron scattering experiment was approved by the Neutron Scattering Program Advisory Committee of IMSS, KEK (Proposal No. 2014S10). C.J.P. is supported by the Royal Society through a Royal Society Wolfson Research Merit Award and the EPSRC through Grant No. EP/P022596/1. The authors thank Dr. A. Nakano at Nagoya University.

\section{REFERENCES}

(1) Badding, J. V. High-pressure Synthesis, Characterization, and Tuning of Solid-State Materials. Ann. Rev. Mater. Sci. 1998, 28, 631-658.
Shimizu, K.; Kimura, T.; Furomoto, S.; Takeda, K.; Kontani, K. Onuki, Y.; Amaya, K. Superconductivity in the Non-magnetic State of Iron under Pressure. Nature 2001, 412,316-318.

Drozdov, A. P.; Eremets, M. I.; Troyan, I. A. renofontov, V; Shylin, S. I. Conventional Superconductivity at 203 Kat High Pressures in the Sulfur Hydride System. Nature 2015, 525, 73-76.

Geballe, Z. M.; Liu, H.; Mishra, A. K.; Ahart, M.; Somayazulu, M.; Meng, Y.; Baldini, M.; Hemley, R. J. Synthesis and Stability of Lanthanum Superhydrides. Angew. Chem. Int. Ed. 2018, 57, 688-692.

Shannon, R. D.; Prewitt, C. T. Coordination and Volume Changes Accompanying High-Pressure Phase Transformations of Oxides. Mater. Res. Bull. 1969, 4, 57-62.

Yagi, T.; Suzuki, T.; Akimoto, S.-I. New High-Pressure Polymorphs in Sodium Halides. J. Phys. Chem. Solids 1983, 44, 135-140.

Jeanloz, R.; Ahrens, T. J.; Mao, H. K.; Bell, P. M. B1-B2 Transition in Calcium Oxide from Shock-Wave and Diamond-Cell Experiments. Science 1979, 206, 829-830.

Varshney, D.; Rathore, V.; Kinge, R.; Singh, R. K. HighPressure Induced Structural Phase Transition in Alkaline Earth $\mathrm{CaX}(\mathrm{X}=\mathrm{S}, \mathrm{Se}$ and $\mathrm{Te}$ ) Semiconductors: NaClType (B1) to CsCl-Type (B2). J. Alloy. Compd. 2009, 484, 239-245.

Yamamoto, T.; Kobayashi, Y.; Okada, T.; Yagi, T.; Kawakami, T.; Tassel, C.; Kawasaki, S.; Abe, N.; Niwa, K.; Kikegawa, T.; Hirao, N.; Takano, M.; Kageyama, H. B1to- $B 2$ Structural Transitions in Rock Salt Intergrowth Structures. Inorg. Chem. 2011, 50, 11787-11794.

Taeck Park, K.; Terakura, K.; Matsui, Y. Theoretical Evidence for a New Ultra-High-Pressure Phase of $\mathrm{SiO}_{2}$. Nature 1988, 336, 670-672.

Kageyama, H.; Hayashi, K.; Maeda, K.; Attfield, J. P.; Hiroi, Z.; Rondinelli, J. M.; Poeppelmeier, K. R. Expanding Frontiers in Materials Chemistry and Physics with Multiple Anions. Nat. Commun. 2018, 9, 772.

Yajima, T.; Takeiri, F.; Aidzu, K.; Akamatsu, H.; Fujita, K.; Yoshimune, W.; Ohkura, M.; Lei, S.; Gopalan, V.; Tanaka, K.; Brown, C. M.; Green, M. A.; Yamamoto, T.; Kobayashi, Y.; Kageyama, H. A Labile Hydride Strategy for the Synthesis of Heavily Nitridized $\mathrm{BaTiO}_{3}$. Nat. Chem. 2015, 7, 1017-1023.

Denis Romero, F.; Leach, A.; Möller, J. S.; Foronda, F.; Blundell, S. J.; Hayward, M. A. Strontium Vanadium Oxide-Hydrides: "Square-Planar" Two-Electron Phases. Angew. Chem. Int. Ed. 2014, 53, 7556-7559.

Kobayashi, G.; Hinuma, Y.; Matsuoka, S.; Watanabe, A.; Iqbal, M.; Hirayama, M.; Yonemura, M.; Kamiyama, T.; Tanaka, I.; Kanno, R. Pure $\mathrm{H}^{-}$Conduction in Oxyhydrides. Science 2016, 351, 1314-1317.

Tang, Y.; Kobayashi, Y.; Masuda, N.; Uchida, Y.; Okamoto, H.; Kageyama, T.; Hosokawa, S.; Loyer, F.; Mitsuhara, K.; Yamanaka, K.; Tamenori, Y.; Tassel, C.; Yamamoto, T.; Tanaka, T.; Kageyama, H. MetalDependent Support Effects of Oxyhydride-Supported Ru, $\mathrm{Fe}, \mathrm{Co}$ Catalysts for Ammonia Synthesis. Adv. Ener. Mater. 2018, 1801772.

Kobayashi, Y.; Tang, Y.; Kageyama, T.; Yamashita, H.; Masuda, N.; Hosokawa, S.; Kageyama, H. TitaniumBased Hydrides as Heterogeneous Catalysts for Ammonia Synthesis. J. Am. Chem. Soc. 2017, 139, 1824018246.

Yamamoto, T.; Zeng, D.; Kawakami, T.; Arcisauskaite, V.; Yata, K.; Patino, M. A.; Izumo, N.; McGrady, J. E.; 
Kageyama, H.; Hayward, M. A. The Role of $\pi$-Blocking Hydride Ligands in a Pressure-Induced Insulator-toMetal Phase Transition in $\mathrm{SrVO}_{2} \mathrm{H}$. Nat. Commun. 2017, 8, 1217.

(18) Yamashita, H.; Broux, T.; Kobayashi, Y.; Takeiri, F.; Ubukata, H.; Zhu, T.; Hayward, M. A.; Fujii, K.; Yashima, M.; Shitara, K.; Kuwabara, A.; Murakami, T.; Kageyama, H. Chemical Pressure-Induced Anion OrderDisorder Transition in LnHO Enabled by Hydride Size Flexibility. J. Am. Chem. Soc. 2018, 140, 11170-11173.

(19) Widerøe, M.; Fjellvåg, H.; Norby, T.; Willy Poulsen, F.; Willestofte Berg, R. NdHO, a Novel Oxyhydride. J. Solid State Chem. 2011, 184, 1890-1894.

(20) Tassel, C.; Goto, Y.; Kuno, Y.; Hester, J.; Green, M.; Kobayashi, Y.; Kageyama, H. Direct Synthesis of Chromium Perovskite Oxyhydride with a High MagneticTransition Temperature. Angew. Chem. Int. Ed. 2014, 53, 10377-10380.

(21) Tassel, C.; Goto, Y.; Watabe, D.; Tang, Y.; Lu, H.; Kuno, Y.; Takeiri, F.; Yamamoto, T.; Brown, C. M.; Hester, J.; Kobayashi, Y.; Kageyama, H. High-Pressure Synthesis of Manganese Oxyhydride with Partial Anion Order. Angew. Chem. Int. Ed. 2016, 128, 9819-9822.

(22) Malaman, B.; Brice, J. F. Etude Structurale de l'hydruroOxyde LaHO Par Diffraction Des Rayons X et Par Diffraction Des Neutrons. J. Solid State Chem. 1984, 53, 44 54.

(23) Nelson, J. R.; Needs, R. J.; Pickard, C. J. High-Pressure $\mathrm{CaF}_{2}$ Revisited: A New High-Temperature Phase and the Role of Phonons in the Search for Superionic Conductivity. Phys. Rev. B 2018, 98, 224105.

(24) Bergsma, J.; Loopstra, B. O. The Crystal Structure of Calcium Hydride. Acta Crystallogr. 1962, 15, 92-93.

(25) Speziale, S.; Duffy, T. S. Single-Crystal Elastic Constants of Fluorite $\left(\mathrm{CaF}_{2}\right)$ to $9.3 \mathrm{GPa}$. Phys. Chem. Miner. 2002, 29, 465-472.

(26) Brese, N. E.; O’Keeffe, M. Bond-Valence Parameters for Solids. Acta Crystallogr. B 1991, 47, 192-197.

(27) Glätzle, M.; Schauperl, M.; Hejny, C.; Tribus, M.; Liedl, K. R.; Huppertz, H. Orthorhombic HP-REOF (RE = Pr, $\mathrm{Nd}, \mathrm{Sm}-\mathrm{Gd})$ - High-Pressure Syntheses and Single-
Crystal Structures $(\mathrm{RE}=\mathrm{Nd}, \mathrm{Sm}, \mathrm{Eu})$. Z. Anorg. Allg. Chem. 2016, 642, 1134-1142.

(28) Prewitt, C. T.; Downs, R. T. High-Pressure Crystal Chemistry. Rev. Mineral. 1998, 37, 284-318

(29) Siegbahn, P. E. M. A Comparative Study of the Bond Strengths of the Second Row Transition Metal Hydrides, Fluorides, and Chlorides. Theor. Chim. Acta 1993, 86, 219-228.

(30) Pickard, C. J.; Needs, R. J. High-Pressure Phases of Silane. Phys. Rev. Lett. 2006, 97, 045504.

(31) Pickard, C. J.; Needs, R. J. Ab Initio Random Structure Searching. J. Phys.-Condens. Mat. 2011, 23, 053201.

(32) Nelson, J. R.; Needs, R. J.; Pickard, C. J. High-Pressure Phases of Group-II Difluorides: Polymorphism and Superionicity. Phys. Rev. B 2017, 95, 054118.

(33) Clark, S. J.; Segall, M. D.; Pickard, C. J.; Hasnip, P. J.; Probert, M. I. J.; Refson, K.; Payne, M. C. First Principles Methods Using CASTEP. Z. Krist. Cryst. Mater. 2005, 220.

(34) Perdew, J. P.; Ruzsinszky, A.; Csonka, G. I.; Vydrov, O. A.; Scuseria, G. E.; Constantin, L. A.; Zhou, X.; Burke, K. Restoring the Density-Gradient Expansion for Exchange in Solids and Surfaces. Phys. Rev. Lett. 2008, 100, 136406.

(35) Beck, H. P. A Structure Refinement of the High Pressure Modification $\mathrm{BaI}_{2}$-II. J. Solid State Chem. 1983, 47, 328332.

(36) Kohlmann, H.; Beck, H. P. Synthesis and Crystal Structure of the gamma-Modifications of $\mathrm{US}_{2}$ and $\mathrm{USe}_{2} . Z$. Anorg. Allg. Chem. 1997, 623, 785-790.

(37) Haase, A.; Brauer, G. Hydratstufen und Kristallstrukturen von Bariumchlorid. Z. Anorg. Allg. Chem. 1978, 441, 181-195.

(38) Machida, A.; Watanuki, T.; Kawana, D.; Aoki, K. Phase Separation of Lanthanum Hydride under High Pressure. Phys. Rev. B 2011, 83, 054103. 


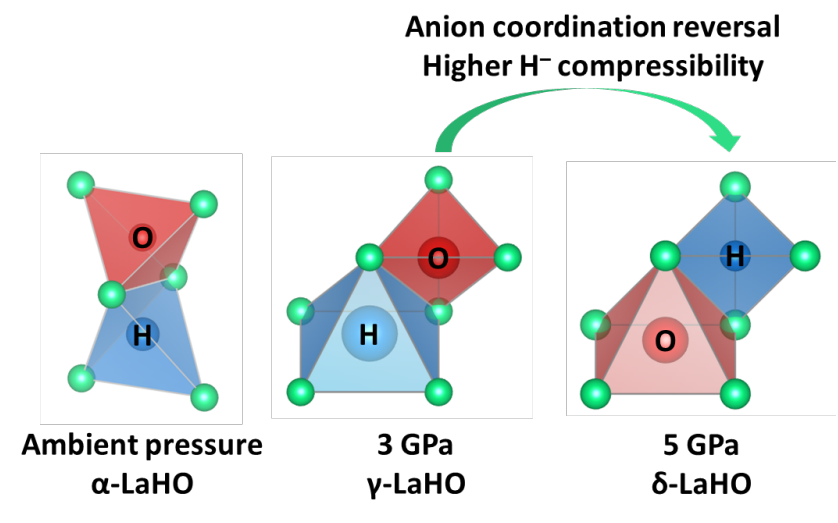

